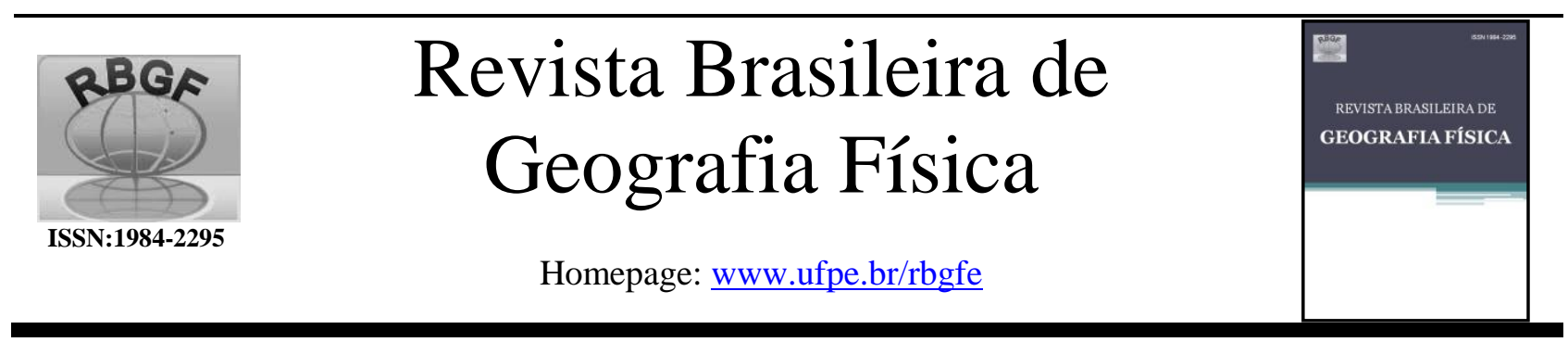

\title{
O Mapeamento Colaborativo: seu surgimento, suas características e o funcionamento das plataformas
}

\author{
João Vitor Meza Bravo' ${ }^{1}$, Claudia Robbi Sluter ${ }^{2}$
}

\begin{abstract}
${ }^{1}$ Doutor em Ciências Geodésicas, Professor Adjunto do Instituto de Geografia da Universidade Federal de Uberlândia, CEP 38.500-000, Monte Carmelo, MG, Brasil. Autor Correspondente: E-mail: jvmbravo@ gmail.com; ${ }^{2}$ Doutora em Computação Aplicada, Professora Associada do Instituto de Geociências da Universidade Federal do Rio Grande do Sul, CEP 91.540-000, Porto Alegre, RS, Brasil. E-mail: robbisluter@ gmail.com Artigo recebido em 06/06/2018 e aceito em 24/08/2018
\end{abstract}

\section{R E S U M O}

O Mapeamento Colaborativo é um contexto de uso dos mapas que se desenvolveu em função do surgimento da Web 2.0. O desenvolvimento das tecnologias da informação mediante o contexto da Web 2.0, possibilitou que indivíduos sem educação formal em Cartografia usassem e produzissem geoinformação. Para se compreender este novo contexto de uso dos mapas é necessário que se apresente e discuta os conceitos, características e tecnologias que orbitam a temática do mapeamento colaborativo. Nesse sentido, este artigo foi proposto com a intenção de se apresentar uma revisão conceitual sobre o atual estágio em que se encontram as discussões acadêmicas sobre a temática do mapeamento colaborativo. Com este artigo oportuniza-se reflexões que podem gerar pesquisas científicas neste campo do conhecimento..

Palavras-chave: Mapeamento Colaborativo, VGI, Web 2.0, Revisão Conceitual.

\section{Collaborative Mapping: its emergence, characteristics and how does it work}

\begin{abstract}
A B S T R A C T
Collaborative mapping is a new map use context, developed under the Web 2.0 technological structure. Specifically, the Collaborative Mapping applications have enabled individuals without education in Cartography and GIS to use and produce geoinformation. Consequently, it is necessary to discuss the concepts, the characteristics, and the technologies surrounding this new map use context, to comprehend its dynamics and to visualize research opportunities. In this paper we have presented a conceptual review about the Collaborative Mapping subject, its emergence, characteristics, and how does it work, hoping to provide insights into the research opportunities, as well as, to give a conceptual background for the other researchers whose interest lies upon this topic.
\end{abstract}

Keywords: Collaborative Mapping, VGI, Web 2.0, Review.

\section{Introdução}

Neste artigo apresenta-se uma revisão sobre o tema mapeamento colaborativo, seu surgimento, características e funcionamento. $\mathrm{O}$ mapeamento colaborativo é um novo contexto de uso dos mapas que demanda atenção dos pesquisadores em Cartografia (Griffin et al., 2017). Para que seja possível compreender o mapa colaborativo é necessário conhecer os conceitos, as características e as tecnologias que que o definem e o compõem. Assim, este artigo foi construído com o propósito de estimular e apoiar as pesquisas acadêmicas neste novo contexto de produção e uso de mapas.

Foi na primeira década do século XXI que os mapas passaram a ser usados, principalmente, em dispositivos móveis e computadores pessoais
(Elwood et al., 2012; Griffin \& Fabrikant, 2012; Van Elzakker \& Griffin, 2013; Ferster e Coops, 2013). Estes dispositivos, por sua vez, estão permanentemente conectados à rede mundial de computadores (Warf, 2011). Tal constatação se torna importante para o tema deste artigo, pois Nyerges (1991) e Van Elzakker (2004) - apud Bravo (2017) - afirmam que a tecnologia altera o modo como as pessoas utilizam os mapas. Sendo o mapa, neste caso, um produto apresentado em dispositivos que são móveis e que estão conectados à Internet, é possível afirmar que um dos maiores impactos desta transformação tecnológica está na ampliação dos possíveis contextos em que os mapas são usados (Griffin e Fabrikant, 2012; Van Elzakker e Griffin, 2013; Griffin et al., 2017). Entretanto, para se discutir tais impactos é 
necessário que, inicialmente, se compreenda as características das tecnologias que tornaram essa realidade possível.

Nesse sentido, a discussão apresentada neste artigo inicia com uma breve introdução sobre a Internet e suas evoluções em características conceituais: de Web 1.0 para Web 2.0. Em seguida, apresenta-se os sistemas Web 2.0 e a estrutura das plataformas geradas a partir desse conceito. Com efeito, atenção especial é dada aos sistemas Web 2.0 que envolvem a prática do mapeamento. Adiante, quando se aborda a temática do mapeamento colaborativo com foco nas informações geográficas voluntárias, introduz-se na discussão os modelos de estrutura e o funcionamento das plataformas VGI, bem como, os aspectos da qualidade de dados a elas associados. No final deste artigo, caracteriza-se a plataforma OpenStreetMap como um exemplo representativo de tecnologia de mapeamento colaborativo/VGI.

\section{Evolução conceitual da Web 1.0 para Web 2.0: bases à formação das plataformas de mapeamento colaborativo}

Durante as duas últimas décadas, cresceu a demanda pela utilização de tecnologias da informação, consequência do ativo desenvolvimento de dispositivos móveis, de softwares e da Web (Griffin e Fabrikant, 2012; Van Elzakker e Griffin, 2013; Buchroithner e Gartner, 2013; Ferster e Coops, 2013). A literatura especializada em Cartografia é consensual ao entender que os indivíduos da sociedade moderna tiveram que adaptar-se a um novo modelo de interação com os produtos tecnológicos. Este novo modelo de interação promove maior participação dos indivíduos, e portanto é democrático e estimula o engajamento social (Jarret, 2008; Ferster e Coops, 2013; Proferes, 2016; Jamieson, 2016).

A disponibilidade e o acesso ao conteúdo da Internet aumentou proporcionalmente às modificações nas estruturas das plataformas Web, antes idealizadas com o conceito de Web 1.0, depois, sob a Web 2.0, que tem o forte caráter de ser participativa (Newman et al., 2016). Segundo Cormode e Krishnamurthy (2008), a Web 1.0 é considerada a "velha web", os primórdios da criação da rede. Na Web 1.0 os hiperlinks formavam o laço máximo de interação entre os usuários e as plataformas (Fischer, 2010) e as ações de construção de conteúdo eram somente permitidas aos "alimentadores-proprietários" dos sistemas (Fischer, 2010; Newman et al., 2016). Com a popularização dos computadores pessoais e, principalmente, com o desenvolvimento de dispositivos móveis e a ampliação do uso desses produtos, instigou-se o aprimoramento das plataformas Web que passaram a suportar interações mais complexas, como, por exemplo, permitir que quaisquer indivíduos postassem, apagassem ou modificassem o conteúdo disponível (Jarret, 2008; Ferster e Coops, 2013; Proferes, 2016; Jamieson, 2016, Newman et al., 2016). Cormode e Krishnamurthy (2008) indicam que essas novas possibilidades de interações traduzem o que se caracterizou, mais adiante, como o conceito de Web 2.0.

Na concepção da Web 2.0 os usuários das plataformas podem participar do gerenciamento do conteúdo numa perspectiva mais dinâmica, i.e., neste novo modelo as pessoas, que antes eram apenas "consumidoras" de conteúdo, passaram, também, a produzi-lo, por diversas razões e finalidades, utilizando, principalmente, as redes sociais e sistemas com características colaborativas (Jarret, 2008; Coleman et al., 2009; Ferster e Coops, 2013; Proferes, 2016; Jamieson, 2016; Newman et al., 2016). Gómez-Barrón et al. (2016) destacam que as principais características dos sistemas Web 2.0 são: (1) grande interatividade, (2) interoperabilidade e (3) arquitetura orientada a serviços. Neste caso, os serviços podem ser considerados softwares que são construídos de modo a permitir fácil conexão com outros componentes de softwares. A construção de ferramentas computacionais realizada deste modo visa, principalmente, facilitar a reutilização, a distribuição e a disseminação dessas aplicações (Newman et al., 2016). Nesse sentido, os serviços na Web 2.0 são mecanismos elaborados segundo um determinado padrão que permitirá a interoperabilidade entre as plataformas. A característica de interatividade pode ser implementada de modo a permitir que os usuários destes serviços criem, modifiquem, qualifiquem e compartilhem conteúdo (Jarret, 2008; Jones e Weber, 2012).

Por conta do crescimento e aderência dos sistemas Web 2.0 ao cotidiano das pessoas, alcançou-se aquilo que alguns pesquisadores chamaram de "democratização" do conhecimento postado na Internet (Jarret, 2008; Haklay, 2013; Proferes, 2016). De modo prático, os indivíduos têm, neste contexto, liberdade para modificar o conteúdo disponibilizado, opinar sobre as informações postadas e validar ou invalidar ações de terceiros (Goodchild, 2007; Jarret, 2008; Proferes, 2016). Esta democratização na construção de conhecimentos é, ao mesmo tempo, causa e consequência da disseminação de uma abordagem mais participativa, e tem afetado o modo como companhias interagem com seu público, no modo como pesquisadores 
desenvolvem suas investigações, entre outras situações (Sieber, 2006; Haklay, 2013; Griffin e Fabrikant, 2012).

Exemplos de sistemas Web 2.0 podem ser facilmente encontrados na rede, como os sistemas com formato de redes sociais (e.g, Facebook, Instragram, Flickr), sistemas para disseminação de conteúdo diverso (e.g. Wikipedia) ou mesmo sistemas de disseminação de informações geográficas (Openstreetmap, Wikimapia, Ushahidi). Neste artigo o foco orienta-se à exploração de algumas das características essenciais à constituição das plataformas Web 2.0 direcionadas ao uso, produção e disseminação de informações geográficas, conhecidas como plataformas de mapeamento colaborativo (Elwood et al., 2012).

\section{As plataformas de mapeamento colaborativo, suas características e funcionamento}

Os avanços tecnológicos ocorridos no início da década de 1990 são considerados o principal gatilho que alterou o uso e produção de geoinformação nos anos subsequentes (Goodchild, 2007; Haklay et al., 2008; Heipke, 2010; Perkins, 2011; Elwood et al., 2012; Bravo e Sluter, 2015). Nesse contexto, o interesse das pessoas em participar da criação do conteúdo disponível na Web foi determinante para o surgimento de um novo padrão de interação nos sistemas Web (O’Reilly, 2007). Se na Web 1.0 as pessoas não podiam avançar no modo de interagir com o conteúdo disponível além de um simples clique em um hiperlink, na Web 2.0 puderam postar, divulgar, e modificar informações (O'Reilly, 2007; Cormode e Krishnamurphy, 2008). Desta forma, a estrutura da Web 2.0 permite o desenvolvimento de aplicações tais como, Facebook, YouTube, Instagram, FlickR, Wikipedia, nas quais uma parte do conteúdo é gerado e disponibilizado pelos próprios usuários (Budhathoki et al., 2008; West et al., 2012; Jamieson, 2016; Newman et al., 2016). Este processo de criação da informação pelos usuários é comumente chamado de "user-generated content" (McKenzie et al., 2012) e os usuários são os "produsers", pois são agentes capazes de usar, modificar e produzir informação (Budhathoki et al., 2008).

Na dinâmica imposta pela Web 2.0, além de divulgar fotos, mensagens, vídeos e outros conteúdos, os indivíduos querem, também, disseminar a posição em que se encontram, divulgar a localização de um restaurante de sua preferência, ou, ainda, ajudar a mapear lugares distantes que sofrem com fatídicos desastres naturais (Liu e Palen, 2010; Heipke, 2010; Zook et al., 2010). Nesse sentido, o conceito de Web 2.0 aplicado ao contexto das informações geográficas é chamado de Geoweb (Haklay et al., 2008; Gómez-Barrón et al., 2016). A Geoweb é considerada uma porção da Internet que é utilizada para disseminar informações geográficas. Assim, atua como uma grande plataforma em que se reúne, analisa e compartilha dados espaciais, com serviços Web desenvolvidos para se permitir grande interatividade e interoperalidade (Haklay et al., 2008; Gómez-Barrón et al., 2016). Tais características permitem que os usuários criem, modifiquem, compartilhem dados georreferenciados, uma modalidade de "usergenerated content". Exemplos de produtos da Geoweb são os sistemas de mapeamento colaborativo, como o Google Map Maker, o OpenStreetMap e o Wikimapia (Rouse et al., 2007; Goodchild, 2007; Chilton, 2011; Perkins, 2011).

A existência dessa dinâmica participativa no mapeamento de feições, se deu pelo desenvolvimento dos sistemas de posicionamento instalados nos dispositivos móveis, com valores financeiros cada vez mais acessíveis a todas as camadas da população (Griffin e Fabrikant, 2012). Por conseguinte, atentos a esses movimentos e instigados pela necessidade dos usuários de aplicações Web em divulgar o próprio conteúdo e posição geográfica, grandes corporações como Google, Nokia, Apple, Microsoft introduziram esforços no campo de produção de bases cartográficas (Rouse et al., 2007; Perkins, 2011). É, portanto, nesse contexto, aliado ao crescimento dos movimentos "Open Source" (Pomerantz e Peek, 2016), que surgiram alternativas livres, voltadas à disseminação do conteúdo geográfico na Web: as plataformas de mapeamento colaborativo (Elwood et al., 2012).

Vale a pena salientar que existem importantes diferenças conceituais que devem ser ponderadas durante o processo de compreensão destas tecnologias (Buchroithner e Gartner, 2013; See et al., 2016). Nesse sentido, entende-se que é necessário definir o que significam as expressões "crowdsourcing", "mapeamento colaborativo" e "informação geográfica voluntária".

A expressão "crowdsourcing" retrata o método para se cumprir uma tarefa, como, por exemplo, resolver um problema ou coletar uma informação, utilizando uma chamada aberta de colaboração (Howe, 2006; Sieber, 2015). As contribuições no contexto do "crowdsourcing" são feitas online, por meio de sites interativos que utilizam a estrutura da Web 2.0 (Sieber, 2015). Paralelamente, "mapeamento colaborativo" é a expressão utilizada para determinar a natureza colaborativa do compartilhamento de informação 
geográfica nas plataformas Web 2.0 (Rouse et al., 2007; Perkins, 2008; See et al., 2016). A expressão "mapeamento colaborativo" guarda consigo uma conotação de empoderamento de comunidades e cidadãos que antes não participavam do processo de criação das informações geográficas (Sieber, 2006; Rouse et al., 2007). Por outro lado, a "informação geográfica voluntária" - IGV ou VGI - é um tipo especial de "user-generated content", assim como afirmou Goodchild (2007). A expressão "VGI" refere-se às informações geográficas coletadas e compartilhadas voluntariamente pelo público geral e, por público geral, compreende-se indivíduos sem necessariamente educação formal em Cartografia (See et al., 2016; Ooms et al., 2015). Importante destacar que, neste último caso, a ação praticada deve ser do tipo voluntária, sem qualquer estímulo que não seja a própria motivação de compartilhar o conteúdo (Elwood et al., 2012; Sieber E Haklay, 2015; Gómez-Barrón et al., 2016; See et al., 2016). De todo o modo, ao se conceituar tais expressões neste artigo, compreende-se que as plataformas de mapeamento colaborativo abrangem, também, as plataformas VGI.

Nesse sentido, o crescente uso das plataformas de mapeamento colaborativo (e.g. OpenStreetMap, Wikimapia) tem promovido avanços nas habilidades, de indivíduos sem educação formal em Cartografia, para a coleta, a produção, o compartilhamento e a interação com as informações geográficas online (Elwood et al., 2012; Jones e Weber, 2012; Sieber, 2015). Por conta da riqueza nos metadados e do potencial de atualização e incorporação de conhecimento local nos dados oficiais (Camboim et. al., 2015; Bravo et al., 2015), as agências oficiais de mapeamento de diferentes países têm adotado princípios colaborativos para a construção de suas bases de dados espaciais (Pourabdollah et al. 2013; Dorn et al., 2015; Olteanu-Raimond et al., 2017). Geralmente, essas bases colaborativas são construídas segundo eixos temáticos específicos, os quais abrangem informações adicionais àquelas dos levantamentos convencionais (Elwood et al., 2012).

O projeto estadunidense "The National Map Corps" (Figura 1) é um exemplo de uma inciativa governamental que visa incorporar dados não-oficiais à base cartográfica oficial de um país inteiro. Esta é uma proposta subsidiada pelo Serviço Geológico Norte-Americano (USGS) e permite que os cidadãos coletem, atualizem e disponibilizem informações que compõem parte do mapeamento de referência dos Estados Unidos (Bearden, 2007)

É interessante notar que países com uma estrutura de mapeamento sistemático consolidada preocupam-se em se alinhar com as tendências tecnológicas de modo a utilizar, por exemplo, informações geográficas voluntárias como complemento às suas bases cartográficas oficiais (Bearden, 2007; Pourabdollah et al. 2013; Dorn et. al, 2015; Olteanu-Raimond et al., 2017). Por exemplo, Olteanu-Raimond et al. (2017) relatam o uso de VGI em agências oficias de mapeamento de diversos países da união europeia. Entretanto, esta não é uma tendência que se observa em países em desenvolvimento, como o Brasil (Bravo, 2014; Camboim et al., 2015; Bravo et al., 2015; Bravo e Sluter, 2015). Para Camboim et al. (2015), por exemplo, as informações geográficas voluntárias poderiam auxiliar a complementação - ou substituição - das bases cartográficas oficiais de países que, assim como indicaram Estes e Mooneyhan (1994), sofrem com a escassez de geoinformação.

Diversos campos de aplicações têm sido favorecidos com o uso dos dados produzidos com mapeamento colaborativo. Por exemplo, Upton e Dunham (2015) combinaram informações geográficas oficiais da Irlanda com informações geográficas voluntárias, para mapear recursos recreacionais em reservas florestais irlandesas. Esses autores destacam que a falta de informações oficiais é o principal motivo pela busca de alternativas como a oferecida pelas plataformas VGI. Similarmente, Ramahtizadeh et al. (2016) investigaram a possibilidade do uso de VGI na administração de territórios. Nesta proposta, as informações geográficas voluntárias serviriam como complemento à coleta oficial de dados relativos aos direitos, restrições e responsabilidades dos cidadãos e do Estado, no que se refere ao uso, manejo e administração da terra.

Entretanto, é comum observar na literatura questionamentos que penalizam o uso do VGI para finalidades oficiais, uma vez que, as informações geográficas produzidas por voluntários nem sempre alcançam a qualidade que das produzidas por órgãos oficiais de mapeamento (Haklay, 2010; Haklay et al., 2010). Para se discutir a qualidade de dados no contexto do VGI, entende-se que, primeiramente, deve-se compreender o funcionamento destas plataformas e esta é a questão que se aborda no próximo item. 


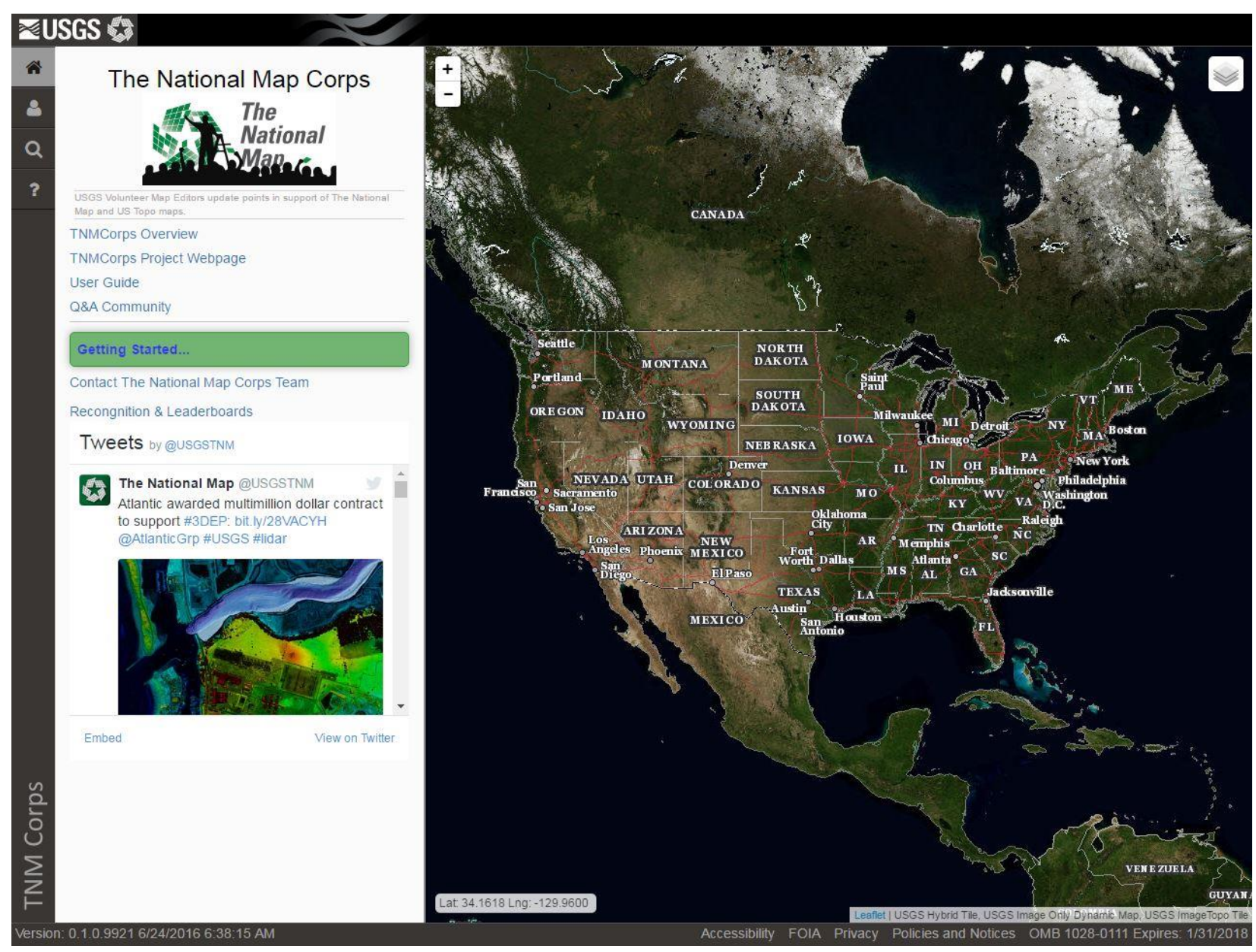

Figura 1. Página de edição do projeto “The National Map Corps” (USGS, 2017).

\section{Resultados e discussão}

Variáveis Ambientais

4 Os modelos de funcionamento das plataformas VGI e a questão da qualidade de dados espaciais

É possível verificar na literatura pesquisas )que ilustram a estrutura de funcionamento de plataformas de mapeamento colaborativo (Elwood et al., 2012; Fast e Rinner, 2014; Gómez-Barrón et al., 2016). Estas pesquisas comumente apresentam as características tecnológicas, os atores envolvidos na produção e uso das informações geográficas, bem como, a infraestrutura técnica que é o suporte para a construção destes sistemas (Oxley, 2009; Elwood et al., 2012; Fast e Rinner, 2014; Gómez-Barrón et al., 2016). Claramente, são abordagens que visualizam as plataformas VGI enquanto sistemas de informação, pois, levam em consideração os seguintes componentes: tecnologias, pessoas e processos (Gómez-Barrón et al., 2016). Para melhor ilustrar essas concepções, neste artigo apoia-se nas visões de estrutura de plataformas VGI propostas por Fast e Rinner (2014) e por Gómez-Barrón et al. (2016).
Fast e Rinner (2014) propuseram um modelo estrutural simplificado das componentes das plataformas VGI (Figura 2). Neste caso, podese visualizar que as plataformas VGI são construídas segundo três principais componentes: um projeto, os participantes e a infraestrutura técnica. Fast e Rinner (2014) destacam que o papel dos participantes na composição deste tipo de sistema é diferente daquilo que se tinha com os sistemas Web pretéritos. Isso ocorre, pois, nas plataformas VGI os usuários - com ou sem educação formal em Cartografia - são capazes de fornecer, criar, manipular, analisar e apresentar dados espaciais. Essas novas possibilidades só poderiam existir se, e somente se, houvesse uma infraestrutura técnica adequada (Oxley, 2009). A infraestrutura técnica, por sua vez, é um elemento constituído pelos hardware, software e, no caso das plataformas VGI, pelas características da Geoweb. Deste modo, o projeto de um sistema VGI pode assumir certas características que o qualificam como sendo um projeto de mapeamento colaborativo apoiado no voluntariado. 


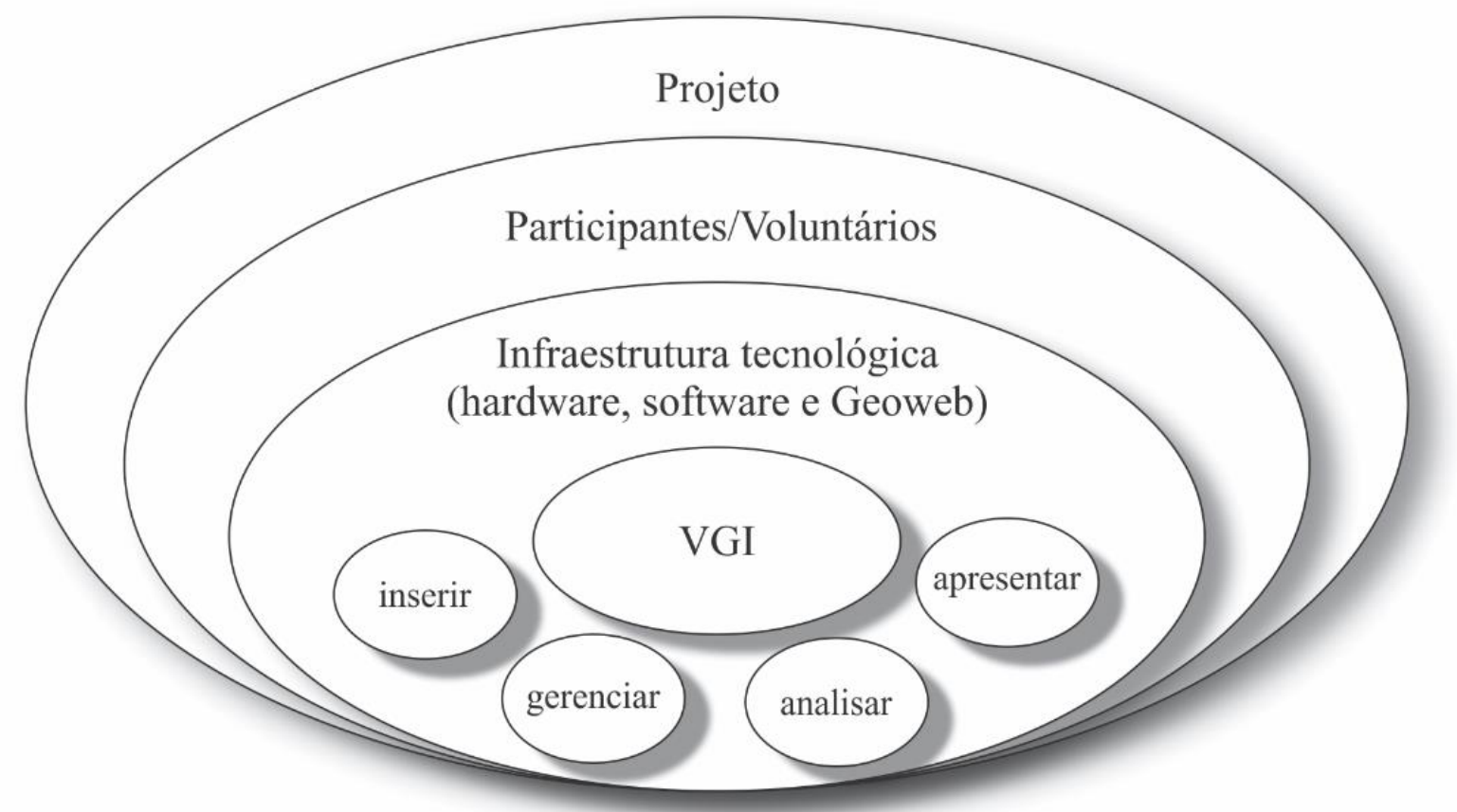

Figura 2. Os componentes dos sistemas VGI, segundo Fast e Rinner (modificado de Fast e Rinner, 2014).

Gómez-Barrón et al. (2016) também ilustraram o funcionamento das plataformas VGI, entretanto, com um esquema mais complexo (Figura 3). Isso pode ser afirmado, pois, quando comparado com o modelo de Fast e Rinner (2014), o modelo de Gómez-Barrón et al. (2016) apresenta um maior detalhamento sobre os atores envolvidos na dinâmica de uso e produção do VGI, bem como, na trajetória dos processos atrelados a esta dinâmica. Gómez-Barrón (2016) assim o fazem, pois, consideram que "o estudo genérico sobre um sistema consiste em identificar suas partes e interações entre estes componentes" (GómezBarrón et al., 2016).

Nesse sentido, ao observar o modelo proposto por Gómez-Barrón et al. (2016), percebese que estes autores consideram que as plataformas VGI são compostas pelos seguintes elementos: o projeto (virtual ou híbrido), os participantes (quaisquer indivíduos ou comunidades de indivíduos), as contribuições (dados geográficos e conteúdo) e as tecnologias de informação e comunicação (e.g. serviços web). Gómez-Barrón et al. (2016) indicam que o elemento "projeto" está relacionado ao conjunto de ações e processos requeridos para se cumprir uma tarefa. Preferiram chamar de "projeto", pois acreditam que tal conjunto de ações e processos dependem das premissas do sistema - ou projeto VGI - em que são executadas as tarefas. Porque as plataformas VGI priorizam os requisitos sociais e pessoais dos voluntários, Gómez-Barrón et al. (2016) afirmam que a maior parte de uma plataforma de mapeamento colaborativo depende dos voluntários (participantes) que postarão os dados (contribuições) conforme os objetivos do "projeto". Os processos organizacionais, neste caso, são os procedimentos para se adquirir e manipular os dados. Gómez-Barrón et al. (2016) indicam que as plataformas VGI comumente utilizam as práticas do tipo "crowdsourcing" para adquirir e possibilitar a manipulação dos dados geográficos. Em seguida, os objetivos organizacionais ilustram as finalidades para as quais são desenhados estes "sistemas". Importante salientar que, Gómez-Barrón et al. (2016) consideram as plataformas VGI como sistemas de informação, os quais servem a três principais propósitos: (1) para aquisição de conhecimento espacial, (2) para a solução de problemas geográficos e (3) para a formação de ideias. 


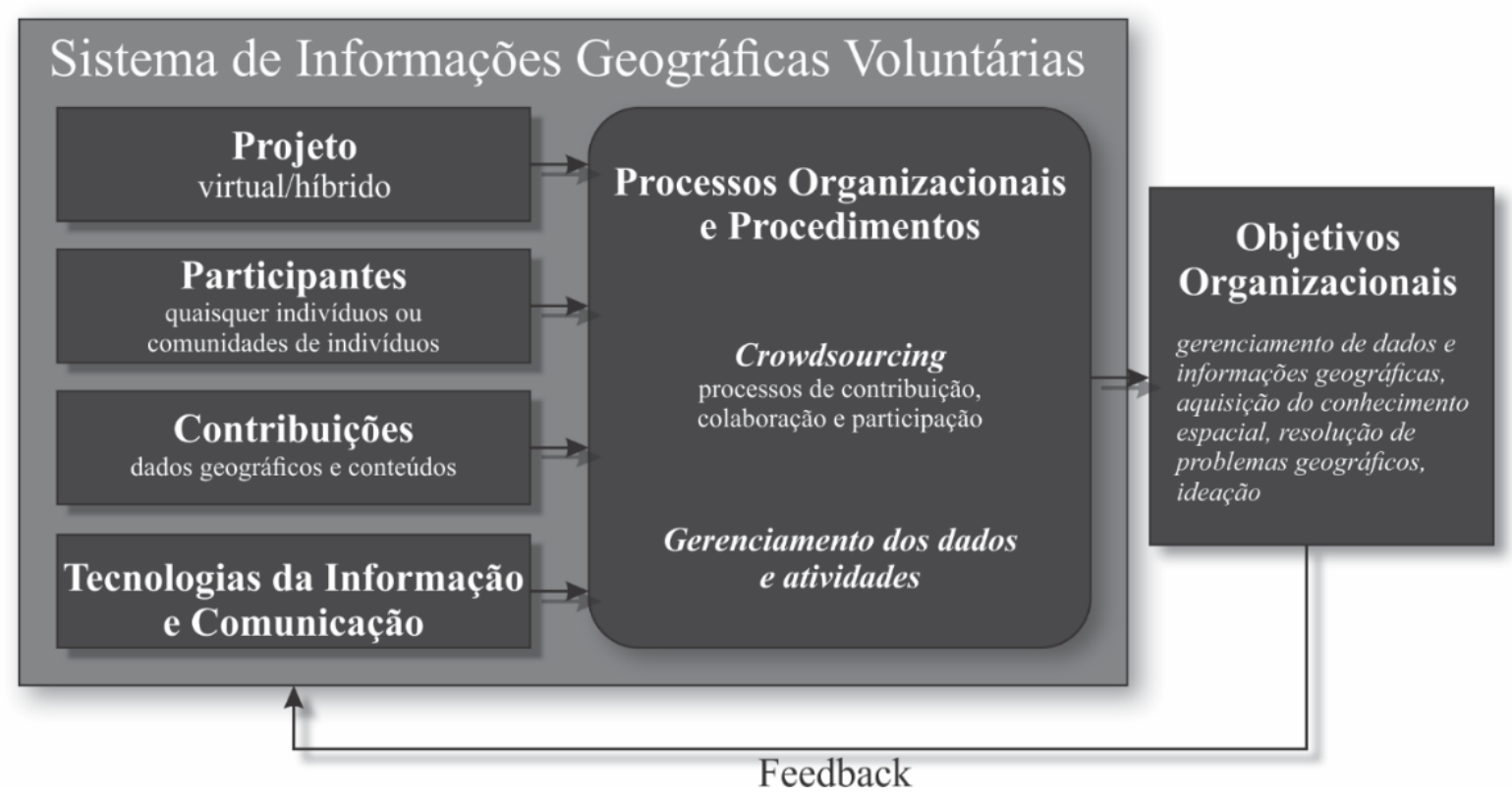

Figura 3. Modelo estrutural geral de uma plataforma VGI, segundo Gómez-Barrón et al. (modificado de Gómez-Barrón et al., 2016).

Para melhor compreender o funcionamento das plataformas de mapeamento colaborativo é necessário conhecer algumas das características que facilitam o processo de colaboração, posto que a ação de colaboração é o canal que viabiliza a existência desta tecnologia. Essa discussão é feita no próximo item.

\subsection{Características que facilitam a prática de colaboração nas plataformas de mapeamento colaborativo}

Neste artigo, determinação das características que facilitam a prática de colaboração nas plataformas de mapeamento colaborativo fundamenta-se, principalmente, nas pesquisas de Elwood et al. (2012) e Gómez-Barrón et al. (2016). Tais pesquisas cobrem a necessidade de se avaliar as propriedades mais relevantes, das plataformas, que facilitam a prática do mapeamento colaborativo, pois compartilham um ponto de vista genérico. Nesse sentido, Elwood et al. (2012) e Gómez-Barrón et al. (2016) concentraram esforços na elaboração de um panorama sobre: (i) o conteúdo e as características gerais das plataformas de mapeamento colaborativo (Elwood et al., 2012; Gómez-Barrón et al., 2016), (ii) os processos tecnológicos e sociais pelos quais tais plataformas são construídas (Elwood et al., 2012) e (iii) o entendimento sobre o funcionamento destas plataformas (GómezBarrón et al., 2016). Ao estudar estas características foi possível gerar um quadro (Quadro 1) que sintetiza as que facilitam a ação de colaboração nas plataformas de mapeamento colaborativo.

Elwood et al. (2012) inventariaram características de noventa e nove (99) plataformas VGI existentes em todo o mundo. Para tanto, buscaram distinguir os seguintes aspectos: a extensão ou alcance geográfico das informações geográficas nelas postadas, a data em que a plataforma foi criada, o tipo da organização ou grupo que começou o projeto e, por último, o propósito da iniciativa. Para Elwood et al. (2012), a extensão ou alcance geográfico das informações postadas nas plataformas VGI pode ser local, regional ou global. A data de criação variou segundo as seguintes classes de períodos: "pré2000", “2000-2004”, “2005-2009”, “sem identificação". Os tipos de organizações ou grupos que iniciaram os projetos, foram classificados de acordo com as categorias: "instituição com fins lucrativos", "individual ou coletivo", "organização não-governamental", "governo", “academia", "entidades com múltiplos patrocínios".

Elwood et al. (2012) inventariaram tais informações por intermédio de consultas diretas às bases de dados destas plataformas, utilizando de métodos das pesquisas qualitativas (Suchan e Brewer, 2000). Apesar de fundamentarem suas discussões em uma amostra numericamente limitada de plataformas VGI, esses autores afirmam que sua pesquisa oferece uma visão panorâmica e sistemática sobre as características 
das iniciativas VGI existentes. Portanto, as características levantadas por Elwood et al. (2012) compõem parte dos elementos presentes no quadro de caracterização elaborado nesta revisão (Quadro $1)$.

Paralelamente, sabe-se que a prática do voluntariado aplicada à Cartografia pode ser fruto de diversas motivações dos indivíduos participantes das plataformas de mapeamento colaborativo (Coleman et al., 2009; Budhathoki e Haythornthwaite, 2012). Essa diversidade de motivações resulta em produtos com características específicas, as quais foram levantadas por GómezBarrón et al. (2016).

Gómez-Barrón et al. (2016) consideram que, a prática do compartilhamento e a possibilidade de geração do conteúdo são aspectos que caracterizam essas plataformas como elementos distintos no universo de produtos cartográficos (Goodchild, 2007; Elwood et al., 2012; Gómez-Barrón et al., 2016). De modo oposto ao que ocorre com o uso dos produtos cartográficos profissionais, os produtos do VGI têm seu uso disseminado, pois seu compartilhamento não encontra barreiras ou restrições de acesso (Goodchild, 2007), estabelecendo-se enquanto um contraponto à cartografia profissional, operacionalizada pelas agências oficiais de mapeamento ou por empresas privadas. Dessa forma, incluiu-se no Quadro 1 o seguinte elemento de facilitação à colaboração: propósito ou objetivo da iniciativa (Gómez-Barrón et al., 2016).

Dessa forma, para melhor ilustrar o funcionamento das plataformas de mapeamento colaborativo, buscou-se um exemplo representativo dentre os sistemas disponíveis, o OpenStreetMap (Openstreetmap, 2017).
O ano de 2012 foi marcado pela ocorrência um volume pluviométrico baixo, apresentando um total acumulado de $92,2 \mathrm{~mm}^{2} \mathrm{ano}^{-1}$, que foi muito inferior a normal climatológica da região $(510 \mathrm{~mm}$ anuais) (EMBRAPA SEMIÁRIDO, 2013). Essa seca intensa foi ocasionada pelo fenômeno Dipolo do Atlântico, com temperaturas muito positivas na Bacia do Atlântico Norte, que afetaram o deslocamento da Zona de Convergência Intertropical mais ao norte e, consequentemente, a qualidade da estação chuvosa na Região Nordeste (CPTEC, 2012). Em decorrência disso, com exceção da precipitação, foram observados valores médios das variáveis meteorológicas acima da normal climatológica da região, destacados entre parênteses. Assim, observou-se radiação solar global média anual de $23,15 \mathrm{MJ} \mathrm{m}^{-2} \mathrm{~d}^{-1}(20,15 \mathrm{MJ}$ $\left.\mathrm{m}^{-2} \mathrm{~d}^{-1}\right)$, temperatura do ar média, máxima e mínima iguais a $26,9{ }^{\circ} \mathrm{C}\left(26,2{ }^{\circ} \mathrm{C}\right), 33,8{ }^{\circ} \mathrm{C}(31,8$ $\left.{ }^{\circ} \mathrm{C}\right)$ e $21,5{ }^{\circ} \mathrm{C}\left(21,5^{\circ} \mathrm{C}\right)$ e umidade relativa média bastante reduzida, com valor médio igual a $48,8 \%$ (58\%) (Figura 2a). Neste caso, a temperatura e a umidade relativa do ar mantiveram um comportamento praticamente constante ao longo do ano. Todos estes elementos associados a velocidade do vento média anual relativamente alta $\left(4,56 \mathrm{~m} \mathrm{~s}^{-1}\right)$ resultaram em demanda atmosférica elevada, com valores de déficit de pressão de vapor médios em torno de 2,5 $\mathrm{kPa}$ (Figura 2c).

O comportamento da radiação solar global teve influencia direta no comportamento da temperatura do solo, que atingiu valores médios diários elevados que oscilaram entre 34 e $38{ }^{\circ} \mathrm{C}$, com mínimos próximos à $26{ }^{\circ} \mathrm{C}$ (Figura $2 b$ ).

\begin{tabular}{|c|c|c|c|}
\hline Características & Variáveis da definição & Literatura & $\begin{array}{l}\text { Hipótese da influência na facilitação } \\
\text { Da colaboração }\end{array}$ \\
\hline $\begin{array}{l}\text { Extensão ou } \\
\text { alcance geográfico } \\
\text { das informações } \\
\text { postadas }\end{array}$ & $\begin{array}{ll}\text { - } & \text { Local } \\
\text { - } & \text { Regional } \\
\text { - } & \text { Global }\end{array}$ & $\begin{array}{l}\text { Elwood et } \\
\text { al. (2016) }\end{array}$ & $\begin{array}{l}\text { Quanto maior a extensão ou alcance } \\
\text { geográfico, maior será a facilitação à } \\
\text { prática colaborativa. }\end{array}$ \\
\hline $\begin{array}{l}\text { Data de criação da } \\
\text { plataforma }\end{array}$ & Ano & $\begin{array}{l}\text { Elwood et } \\
\text { al. }(2016)\end{array}$ & $\begin{array}{l}\text { Plataformas que operam a mais tempo } \\
\text { têm maior quantidade de usuários e de } \\
\text { informações, logo, têm maior } \\
\text { probabilidade de obter engajamento. }\end{array}$ \\
\hline $\begin{array}{l}\text { Tipo da } \\
\text { organização ou } \\
\text { grupo que começou } \\
\text { o projeto e }\end{array}$ & $\begin{array}{ll}\text { - } & \text { Instituição com fins } \\
& \text { lucrativos } \\
\text { - } & \text { Individual/coletivo } \\
\text { - } & \text { Organização não- } \\
\text { governamental } \\
\text { - Governo } \\
\text { - } \\
\text { Academia } \\
\end{array}$ & $\begin{array}{l}\text { Elwood et } \\
\text { al. (2016) }\end{array}$ & $\begin{array}{l}\text { Define a capacidade de interação da } \\
\text { plataforma com os diferentes grupos de } \\
\text { usuários e as diferentes finalidades de } \\
\text { uso. Quanto menor a restrição aos } \\
\text { grupos de indivíduos envolvidos na } \\
\text { definição da entidade, maior será a } \\
\text { facilitação à colaboração. }\end{array}$ \\
\hline
\end{tabular}




\begin{tabular}{|ll|l|l|l|}
\hline & $\begin{array}{l}\text { Entidades com } \\
\text { múltiplos patrocínios }\end{array}$ & & \\
\hline $\begin{array}{l}\text { Propósito objetivo } \\
\text { inciativa }\end{array}$ & $\begin{array}{l}\text { ou da } \\
\text { da }\end{array}$ & $\begin{array}{l}\text { Propósito ou objetivo da } \\
\text { iniciativa (e.g. mapear } \\
\text { informações cartográficas } \\
\text { básicas, possibilitar } \\
\text { práticas científicas, } \\
\text { atualizar dados do setor } \\
\text { privado, etc.) }\end{array}$ & $\begin{array}{l}\text { Gómez- } \\
\text { Barrón et } \\
\text { al. (2016) }\end{array}$ & $\begin{array}{l}\text { Quanto mais abrangente o propósito da } \\
\text { iniciativa, maior será a possibilidade de } \\
\text { atrair maior quantidade de usuários, por } \\
\text { conta da maior diversidade de interesses } \\
\text { envolvidos. }\end{array}$ \\
\hline
\end{tabular}

Quadro 1. Características que promovem a ação de colaboração no mapeamento colaborativo.

De fato, o OpenStreetMap é considerado um exemplo representativo das plataformas de mapeamento colaborativo (Jones e Weber, 2012; Polous et al., 2015), tanto pela escala de abrangência de seu banco de dados, quanto pela pluralidade de finalidades a que atende. Pode-se dizer que o OSM é uma plataforma de mapeamento colaborativo que tem seu uso difundido globalmente (Chilton, 2011; Neis e Zipf, 2012, Jones e Weber, 2012; OpenStreetMap, 2017). O OSM conta com um dos maiores acervos de dados geográficos sobre diversos temas, serve a múltiplos propósitos e sua base de dados tem alcance e extensão geográfica mundial (Chilton, 2011; Jones e Weber, 2012; Elwood et al., 2012; Neis e Zipf, 2012; Openstreetmap, 2017). Adicionalmente, o OSM é uma plataforma exaustivamente estudada pela literatura (Haklay, 2010; Chilton, 2011; Jones e Weber, 2012; Behrens et al., 2015), inclusive em testes com usuários de mapas (Jones e Weber, 2012; Behrens et al., 2015). Tendo em vista estes fatores, compreendeu-se que o OpenStreetMap pode ser considerado um sistema representativo do processo de uso e geração de geoinformação no mapeamento colaborativo. Deste modo, o funcionamento deste sistema é apresentado com maior detalhe no próximo item.

\subsection{A plataforma OpenStreetMap, suas características e seu funcionamento}

Criado por Steve Coast, na Grã-Bretanha, em 2004, o OpenStreetMap consolidou-se como importante aplicação para disseminação do conteúdo geográfico na web, no início da segunda década do século XXI (Rouse et al., 2007; Perkins, 2011; Chilton, 2011; Neis e Zipf, 2012). Segundo Chilton (2011), uma das principais motivações de Coast ao fundar o OpenStreetMap ocorreu em consequência de uma frustação com as restrições do Ordnance Survey para o uso de alguns de seus produtos. Por meio de divulgação simples, i.e., listas de e-mails e eventos pequenos, o
OpenStreetMap ganhou os primeiros usuários colaboradores (OpenStreetMap, 2017).

Nesse sentido, o OpenStreetMap congrega em sua plataforma usuários com diversas motivações (Coleman et al., 2009), especialmente voluntários (Neis e Zipf, 2012; Neis et al., 2013). A meta inicial do OpenStreetMap era permitir a criação de uma base de dados global composta por ruas, estradas e caminhos (Chilton, 2011; Neis e Zipf, 2012). Nesse caso, Steve Coast tinha a intenção de compartilhar esse conteúdo de modo abrangente, sem restrições proprietárias ou de direitos autorais (Perkins, 2011). Nessa aplicação, os usuários poderiam acessar, editar e customizar os mapas, em função de suas necessidades (Rouse et al., 2007). É possível afirmar que tais características foram fundamentais para que o projeto "OpenStreetMap" progredisse como se viu nos anos subsequentes (Haklay et al., 2008). Por conseguinte, o OSM alcançou o status de principal plataforma de mapeamento colaborativo do mundo, na segunda década do século XXI, reunindo em sua base milhões de usuários cadastrados (Perkins, 2011; Chilton, 2011; Neis e Zipf, 2012; Neis et al., 2013 OpenStreetMap, 2017).

Fato importante a ser destacado, o OpenStreetMap é uma das plataformas de mapeamento colaborativo mais difundidas no cenário global (Perkins, 2011). No OpenStreetMap circula um grande volume de informações geográficas, assim como na maioria das plataformas de mapeamento colaborativo (Goodchild, 2007; Haklay et al., 2008; Perkins, 2011; Elwood et al., 2012; Neis et al., 2013). Podese dizer que o grande volume de dados depositado em sua base é algo semelhante ao fluxo dos grandes serviços de mapeamento de referência. Nesse sentido, a base de dados do OpenStreetMap é constantemente atualizada, o que permite e incita, mais uma vez, comparações com o desenvolvimento dos serviços de mapeamento de referência de países como a Grã-Bretanha e os Estados Unidos. 
A plataforma do OpenStreetMap assume as características de sistemas Web 2.0, uma vez que permite que os usuários interajam diretamente com os dados postados em seu domínio. Wolf et al. (2011) explicam que o OpenStreetMap permite a consulta ao seu banco de dados por meio de um browser comum. Essa facilidade é comumente notada em outros sistemas Web 2.0, o que atrai a atenção de usuários com diversos níveis de conhecimento sobre o uso de aplicações computacionais. Isso quer dizer que, esse modelo de interação aproxima usuários de ferramentas complexas, por não exigir nenhum treinamento prévio dos usuários em potencial (Jones e Weber, 2012).

A Figura 9 apresenta os componentes da plataforma OpenStreetMap. Nela é possível visualizar cinco classes principais, as quais permitem a entrada, a manipulação e a visualização dos dados na plataforma. Uma explicação exaustiva sobre cada um dos componentes da Figura 4 foi elaborada pela comunidade do OSM e está disponível em <https://wiki.openstreetmap.org/wiki/Elements>. Para se ter uma ideia geral de seu funcionamento, um usuário que queira acessar o OpenStreetMap o fará por meio de um navegador de sua escolha.
Nesse navegador, digita-se o endereço da página em que está alocada a plataforma, de modo a permitir que este usuário observe uma das possíveis camadas de visualização de dados. Este usuário tem a possibilidade de alternar a visualização das camadas por outras, compostas por diferentes simbologias e representando diferentes feições, i.e., renderizações distintas. O processo de "renderização" ocorre quando os dados geográficos brutos são transformados em representações visuais, os mapas. Apesar de aplicar-se simbologias diversas para promover diferentes renderizações (e.g. a renderização transportes ou a renderização ciclovias), a base de dados é a mesma, e está nos servidores físicos do OpenStreetMap. O acesso é feito através de um navegador comum, meio pelo qual as informações do banco tornam-se disponíveis à visualização de acordo com o filtro de camadas escolhido pelo usuário; há, também, a possibilidade de acesso via sistemas de informações geográficas desktop, os quais permitem a consulta a uma espécie de cópia do banco de dados original.

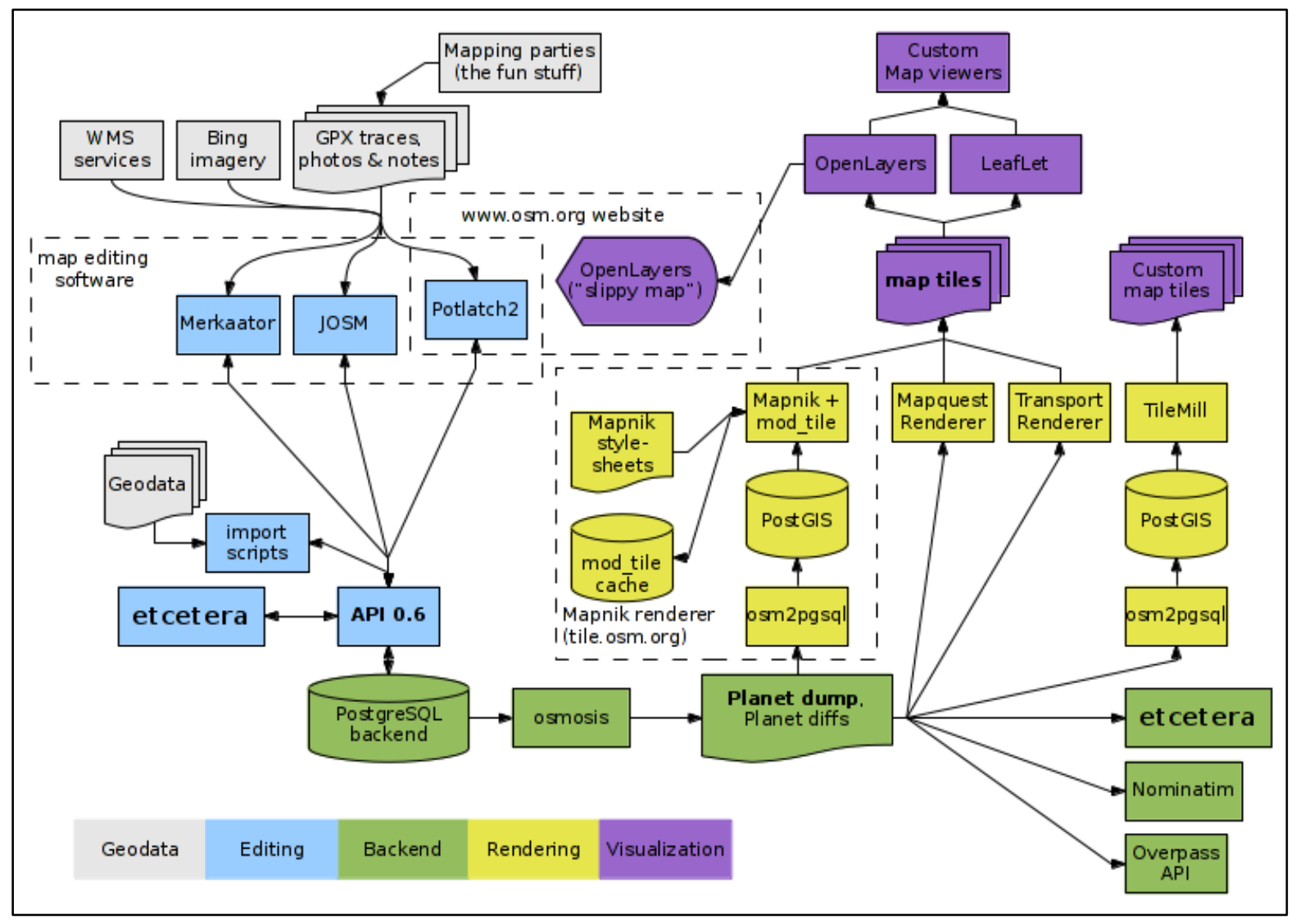

Figura 4. Os componentes da arquitetura do OpenStreetMap (Fonte: OpenStreetMap, 2017). 
Segundo Parr (2015) apud Bravo (2017), os usuários do OpenStreetMap deparam-se com alguns questionamentos comuns durante a ação de colaboração com a plataforma. Parr (2015) apud Bravo (2017), aponta que tais questionamentos são apresentados como escolhas durante o processo de uso da plataforma. Dessa forma, segundo Parr (2015) apud Bravo (2017), os usuários do OpenStreetMap devem, primeiro, decidir sobre qual região geográfica serão feitas as contribuições. Em seguida, esses colaboradores decidirão qual o tipo de feição será mapeada, se devem criar novas feições ou editar outras previamente existentes. Os usuários necessitam pensar como devem ser representadas as feições que serão mapeadas (pontos, linhas ou polígonos), quais os atributos e descrições devem ser incluídos, com qual nível de acurácia uma determinada feição deve ser representada, ou ainda, se sua contribuição será feita em conjunto com outros colaboradores (e.g. mapathon ou OSM mapping party) ou se será feita somente por ele. Parr (2015) apud Bravo (2017) ainda afirma que os usuários do OpenStreetMap precisam decidir se suas contribuições serão agrupadas em um único changeset, i.e., serão feitas e salvas durante uma única fase de trabalho na plataforma, ou se serão feitas em changesets separados. Uma outra tarefa dos "produsers" do OSM relaciona-se com a decisão de quais tipos de categorias usar para cada feição, bem como, qual e quanto de metadados deverão ser incluídos e qual o padrão aderido pelo
OSM. Sobre este último item, aplica-se o conceito de "tags", que são elementos que permitem a descrição das feições postadas no OpenStreetMap, por meio de uma "chave" e um "valor" a ela associado (OpenStreetMap, 2017).

Para contribuir com o OpenStreetMap os usuários da plataforma podem fazê-lo por meio de um browser comum, acessando as interfaces de edição Potlatch 2 ou iD. O Potlach 2 é uma aplicação desenvolvida em AdobeFlash que permite aos usuários do OSM interação direta com o conteúdo alocado na base de dados da plataforma. Existem, também, softwares como o Merkaator e o JOSM, que são ferramentas desktop que permitem a edição do conteúdo no modo offline, para que depois se faça o upload das edições. Todas as informações postadas na plataforma ficam disponíveis na interface de visualização (Figura 5).

É importante indicar que as características gerais e de funcionamento que facilitam a prática de colaboração em sistemas como o OpenStreetMap incitam, também, inquietações na comunidade acadêmica que, na intenção de utilizar o conteúdo disponibilizado neste tipo de plataforma, tem se ocupado com a questão da qualidade associada às informações geográficas voluntárias (Haklay, 2010; Bravo e Sluter, 2015). Desse modo o próximo item aborda os estudos sobre os parâmetros de qualidade das informações geográficas no mapeamento colaborativo.

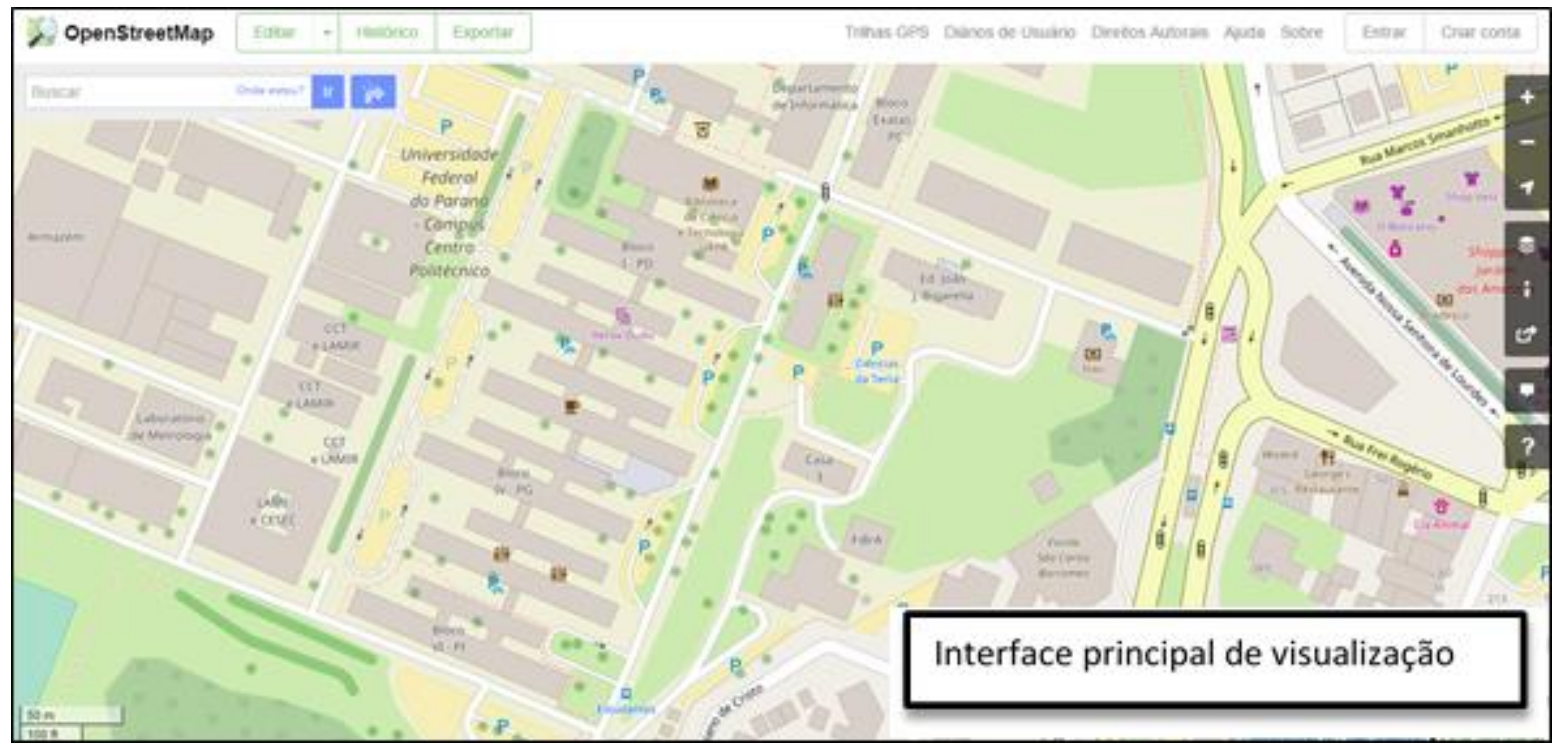

Figura 5. Interface visualização do OpenStreetMap (Fonte: OpenStreetMap, 2017).

4.3 A questão da qualidade das Informações Geográficas no Mapeamento Colaborativo 
Por conta de sua estrutura e características de funcionamento complexos, construídos segundo os moldes das plataformas Web 2.0, a qualidade de dados é tema recorrente na literatura, quando se investiga as informações geográficas postadas nas plataformas de mapeamento colaborativo (Haklay, 2010; Haklay et al. 2010; Heipke, 2010; Goodchild e Li, 2012; Elwood et al., 2012; Comber et al., 2013; Camboim et al.; 2015; Bravo e Sluter, 2015). Isso ocorre devido a entrada de usuários com diversas características dentro do processo de produção do conteúdo: gera-se incertezas sobre a confiabilidade que se pode ter nas informações postadas nestas plataformas (Heipke, 2010; Goodchild e Li, 2012; Elwood et al., 2012; Jones e Weber, 2012; Comber et al., 2013; Bravo, 2014; Bravo e Sluter, 2015).

Essa preocupação ocorre, também, devido ao fato das plataformas Web 2.0 serem desenvolvidas com a intenção de facilitar a comunicação entre servidores e usuários, segundo a utilização de normas e padrões que permitirão a interoperabilidade dos serviços e a reutilização e disseminação dos dados: incompatibilidades na geração ou postagem dos dados podem corromper a cadeia de comunicação. Organizações como a ISO - International Organization for Stadardization - e a OGC - Open Geospatial Consurtium - têm criado normas e padrões que são amplamente discutidos com a comunidade de desenvolvedores independentes e empresas, para que se facilite a interoperabilidade e para que se evite tais problemas (Heipke, 2010; ISO TC/211). Por exemplo, no Brasil, a Infraestrutura Nacional de Dados Espaciais - INDE-BR - preconiza pela utilização dos padrões da ISO para que sejam aportados em sua plataforma todos os tipos de dados espaciais desenvolvidos por organismos tanto da esfera pública, quanto da privada (Brasil, 2008; Bravo et al. 2015). De todo o modo, as normas sobre qualidade de dados espaciais que são comumente adotadas como padrão internacional, são as da ISO, com a série ISO 19000 (Heipke, 2010; ISO TC/211) ou, no caso do Brasil, derivações destas como, por exemplo, a ET-CQDG - Especificação Técnica para Controle da Qualidade de Dados Geoespaciais (Brasil, 2016).

Nesse sentido, na literatura em Cartografia, a questão da qualidade das informações geográficas voluntárias é estudada por meio de duas principais abordagens, as quais estão em consonância com as normas da ISO: a qualidade posicional e a qualidade semântica. A qualidade posicional está relacionada à acurácia com que são representadas as feições geográficas nas plataformas VGI. Por exemplo, Haklay (2010) desenvolveu um interessante estudo, demonstrando que as informações postadas no OpenStreetMap sobre o território britânico divergiam pouco quando comparadas às posições das feições representadas nos produtos oficiais daquele país. Essa constatação é importante, uma vez que, como outrora afirmado, as informações geográficas voluntárias podem ser aliadas de países que não têm grande extensão do território mapeado, assim como o Brasil (Camboim et al., 2015). De modo geral, o estudo da qualidade posicional das informações geográficas voluntárias tem possibilitado que se verifique a compatibilidade destes dados com aqueles oficiais (Camboim et al., 2015; Bravo et al., 2015; Olteanu-Raimond et al., 2017).

A qualidade semântica das informações geográficas voluntárias têm sido, também, foco das atenções das pesquisas científicas neste campo (Flanagin e Metzger, 2008; Comber et al., 2013; Bravo, 2014; Bravo e Sluter, 2015). Isso ocorre, pois, os dados postados por voluntários guardam riqueza semântica que, somente pessoas inseridas no contexto geográfico de ocorrência de um fenômeno ou feição, poderiam detalhar fidedignamente (Bravo, 2014). Segundo a ISO:19157 (ISO TC/211), associadas à qualidade semântica tem-se a consistência lógica, a usabilidade, a completude, a acurácia temática e a qualidade temporal. São elementos que, no contexto das plataformas VGI, estão relacionados às habilidades e às competências dos usuários produtores, ou, "produsers" (Budhathoki et al., 2008).

\section{Conclusões}

Neste artigo, buscou-se revisar os conceitos, o funcionamento e as características do mapeamento colaborativo. Deste modo, apresentou-se, num primeiro momento, a evolução conceitual desencadeada pelo desenvolvimento das tecnologias da informação e comunicação que transitam no contexto da Internet. Destaque foi dado ao contexto tecnológico da Web 2.0, pois, foi por intermédio das características deste contexto tecnológico que surgiram as plataformas de mapeamento colaborativo. Neste artigo, caracterizou-se tais plataformas, discutindo-se os modelos de estrutura e funcionamento apresentados na literatura. Destaque especial foi dado ao OpenStreetMap, uma vez que esta é a plataforma de maior representatividade no segmento dos sistemas de mapeamento colaborativo. A qualidade de dados foi também objeto de interesse desta revisão, uma vez que este tema ratifica a importância das modificações 
trazidas pela inserção de novos usuários e pelas novas características das plataformas Web 2.0 voltadas ao mapeamento. Foi possível verificar com a literatura revisada que as características das plataformas Web 2.0 produziram modificações na estrutura de uso e produção de dados veiculados na internet. Sendo os mapas produzidos e apresentados em plataformas do mesmo segmento, é possível pensar, então, que as modificações no uso e produção de dados espaciais dentro deste contexto, também ocorreram. Evidenciou-se que plataformas de mapeamento colaborativo são desdobramentos dessas evoluções conceituais, tecnológicas e sociais, o que motivou parte da discussão deste artigo. Revisou-se, portanto, os novos conceitos atrelados a este campo de pesquisa da Cartografia.

É possível ainda destacar que, com a revisão feita neste artigo visualiza-se as lacunas e oportunidades de pesquisa proporcionadas pelo mapeamento colaborativo. Consequentemente, compreende-se que o objetivo principal desse artigo foi alcançado, uma vez que ele oportuniza às investigações futuras, reflexão sobre esta temática latente nas pesquisas científicas em Cartografia.

\section{Agradecimentos}

Os autores agradecem à CAPES e ao CNPq.

\section{Referências}

Bearden, M. J. The National Map Corps, 2007. Disponível em <www.ncgia.ucsb.edu/projects/vgi/docs/positio n/Bearden paper.pdf $>$, acessado em outubro de 2016.

Behrens, J.; Van Elzakker, C. P. J. M.; Schmidt, M. 2015. Testing the usability of OpenStreetMap iD Tool. The Cartographic Journal, 52, 177-184

Brasil. Decreto $n^{\circ}$ 6666, de 27 de novembro de 2008. Institui, no âmbito do Poder Executivo federal, a Infraestrutura Nacional de Dados Espaciais - INDE, e dá outras providências. Brasília, Diário Oficial da União, 27 de novembro de 2008.

Brasil. Ministério da Defesa, Exército Brasileiro. 2016. Norma da Especificação Técnica para Controle de Qualidade de Dados Geoespaciais (ET-CQDG). Disponível em < http://www.geoportal.eb.mil.br/images/PDF/E T_CQDG_1a_edicao_2016.pdf >, acessado em janeiro de 2017.

Bravo, J. V. M. 2014. A confiabilidade semântica das informações geográficas voluntárias como função da organização mental do conhecimento espacial. Dissertação de mestrado, Programa de
Pós-Graduação em Ciências Geodésicas, Universidade Federal do Paraná.

Bravo, J. V. M.; Sluter, C. R. 2015. O problema da qualidade de dados na era das informações geográficas voluntárias. Boletim de Ciências Geodésicas, 21(1): 56-73.

Bravo, J. V. M.; Camboim, S. P.; Mendonça, A. L. A.; Sluter, C. R. 2015. A compatibilidade dos metadados disponíveis em sistemas VGI com o perfil de metadados empregado na Infraestrutura Nacional de Dados Espaciais do Brasil (INDE-BR). Boletim de Ciências Geodésicas 21, 465-483.

Bravo, J.V.M. Identificação e Caracterização de Tarefas de Uso e Geração de Geoinformação no Mapeamento Colaborativo. Tese de doutoramento, Programa de Pós-Graduação em Ciências Geodésicas, Universidade Federal do Paraná.

Buchroithner, M. F.; Gartner, G. 2013. The New Face of Cartography: Why Cartography is Relevant, Attractive and Contemporary. GIM International 27, 23-27.

Budhathoki, N. R.; Bruce, B. C. ; Nedovic-Budic, Z. 2008. Reconceptualizing the role of the user of spatial data infrastructure. GeoJournal 72, 149-160.

Budhathoki, N. R.; Haythornthwaite, C. 2012. Motivation for Open Collaboration: crowd and community models and the case of OpenStreetMap. American Behavioral Scientist 57, 548-575.

Camboim, S. P.; Bravo, J. V. M. \& Sluter, C. R. 2015. An investigation into the completeness of, and updates to, the OpenStreetMap data in a heterogeneous area in Brazil. ISPRS International Journal of Geo-Information 4, 1366-1388.

Chilton, S. 2011. OS and OpenStreetMap. Sheetlines 91, 20-27.

Coleman, J. D.; Georgiadou, Y.; Labonte, J. 2009. Volunteered Geographic Information: The nature and motivation of produsers. International Journal of Spatial Data Infrastructures Research 4, 322-358.

Comber, A.; See, L.; Fritz, S.; Van Der Velde, M.; Perger, C.; Foody, G. 2013. Using control data to determine the reliability of volunteered geographic information about land cover. International Journal of Applied Earth Observation and Geoinformation 23, 37-48.

Cormode, G.; Krishnamurthy, B. 2008. Key differences between Web 1.0 and Web 2.0. First Monday 13.

Dorn, H.; Törnros, T.; Zipf, A. 2015. Quality Evaluation of VGI Using Authoritative Data A comparison with land use data in Southern 
Germany. ISPRS International Journal of Geoinformation 4, 1657-1671.

Elwood, S.; Goodchild, M. F.; Sui, D. Z. 2012. Researching Volunteered Geographic Information: Spatial Data, Geographic Research, and New Social Practice. Annals of the Association of American Geographers 102, 571-590.

Fast, V.; Rinner, C. 2014. A systems perspective on Volunteered Geographic Information. ISPRS International Journal of Geo-Information 3, 1278-1292.

Ferster, C. J.; Coops, N. C. 2013. A review of earth observation using mobile personal communication devices. Computers \& Geosciences 51, 339-359.

Fischer, G. 2010. End-User development and Meta-Design: foundations for cultures of participation. Journal of Organizational and End User Computing 22, 52-82.

Flanagin, A. J.; Metzger, M. J. 2008. The credibility of volunteered geographic information. GeoJournal 72, 137-148.

Gómez-Barrón, J. P.; Manso-Callejo, M. A.; Alcarria, R.; Iturrioz, T. 2016. Volunteered Geographic Information System Design: Project and Participation Guidelines. ISPRS International Journal of Geo-Information 5, 135.

Goodchild, M. F. 2007. Citizens as sensors: the world of Volunteered Geography. GeoJournal 69, 211-221.

Goodchild, M. F.; Li, L. 2012. Assuring the quality of volunteered geographic information. Spatial Statistics 1, 110-120.

Griffin, A. L.; Fabrikant, S. I. 2012. More Maps, More Users, More Devices Means More Cartographic Challenges. The Cartographic Journal 49, 298-301.

Griffin, A. L.; White, T.; Fish, C. Tomio, B.; Huang, H.; Sluter, C. R.; Bravo, J. V. M.; Fabrikant, S.; Bleisch, S.; Yamada, M.; Picanço Jr, P. 2017. Designing across map use contexts: A research agenda. International Journal of Cartography 3, 1-25.

Haklay, M.; Singleton, A.; Parker, C. 2008. Web Mapping 2.0: The Neogeography of GeoWeb. Geography Compass 2, 2011-2039.

Haklay, M. 2010. How good is a Volunteered Geographical Information? A comparative study of OpeenStreetMap and Ordnance Survey datasets. Environmental Planning B, Planning Dev. 37, 682-703.

Haklay, M. M.; Basiouka, S.; Antoniou, V.; Ather, A. 2010. How Many Volunteers does it take to map na area well? The validity of Linus's law to
Volunteered Geographic Information. The Cartographic Journal 47, 315-322.

Haklay, M. 2013. Neogeography and the delusion of democratisation. Environment and Planning A 45, 55-69.

Heipke, C. 2010. Crowdsourcing Geospatial Data. ISPRS Journal of Photogrammetry and Remote Sensing 65, 550-557.

Howe, J. 2006. The Rise of crowdsourcing. Wired Magazine. Disponível em <https://www.wired.com/2006/06/crowds/>, acessado em julho de 2016.

ISO 19157: Geographic Information - Data Quality. 2011. International Organization for Standardization

Jamieson, J. 2016. Many (to platform) to many: Web 2.0 application infrastructures. First Monday 21.

Jarret, K. 2008. Interactivity is evil! A critical investigation of Web 2.0. First Monday 13.

Jones, C.; Weber, P. 2012. Towards usability engineering for online editors of Volunteered Geographic Information: a perspective on learnability. Transactions in GIS 16, 523-544

Liu, S.; Palen, L. 2010. The New Cartographers: Crisis Map Mashups and the Emergence of Neogeographic Practice. Cartography and Geographic Information Science 37, 69-90.

McKenzie, P. J.; Burkel, J.; Wong, L.; Whippney, C.; Samuel, E.; Mcnally, M. 2012. Usergenerated online content 1: Overview, current state and context. First Monday, 17.

Neis, P.; Zielstra, D.; Zipf, A. 2013. Comparison of Volunteered Geographic Information Data Contributions and Community Development For Selected World Regions. Future Internet 5, 282-300.

Neis, P.; Zipf, A. 2012. Analyzing the Contributor Activity of a Volunteered Geographic Information Project - The Case of OpenStreetMap. ISPRS International Journal of Geo-Information 1, 146-165

Newman, R. Chang, V.; Walters, R. J.; Wills, G. B. 2016. Web 2.0 - The past and the future. International Journal of Information Management 36, 591-598

Nyerges, T. L. 1991. Analytical Map Use. Cartography and Geographic Information Systems 18, 11-22.

O'reilly, T. 2007. What is Web 2.0: Design patterns and business models for the next generation of software. Communications \& Strategies 65, 1737.

Olteanu-Raimond, A. M.; Hart, G.; Foody, G. M.; Touya, G.; Kellenberger, T.; Demetriou, D. 2017. The Scale of VGI in map production: a 
perspective on European National Mapping Agencies. Transactions in GIS 21, 74-90.

Ooms, K.; De Meyer, P.; Fack, V. 2015. Listen to the the Map User: Cognition, Memory, and Expertise. The Cartographic Journal 52, 3-19.

OpenStreetMap. 2017. Disponível em <www.openstreetmap.org>, acessado em janeiro de 2017.

Oxley, A. 2009. Web 2.0 Applications of Geographic and Geospatial Information. Bulletin of the American Society for Information Science and Technology 35, 43-48.

Perkins, C. 2008. Cultures of Map Use. The Cartographic Journal 45, 150-158.

Perkins, C. 2011. Researching mapping: methods, modes and moments in the (im)mutability of OpenStreetMap. Global Media Journal 5, 1-12.

Polous, K.; Krisp, M. J.; Meng, L.; Shrestha, B.; Xiao, J. 2015. OpenEventMap: A Volunteered Location-Based Service. Cartographica 50, 248-258.

Pomerantz, J.; Peek, R. 2016. Fifty shades of open. First Monday, 21.

Pourabdollah, A.; Morley, J.; Feldman, S.; Jackson, M. 2013. Towards an Authoritative OpenStreetMap: Conflating OSM and OS OpenData National Map's Road Network. ISPRS International Journal of GeoInformation 2, 704-728.

Proferes, N. 2016. Web 2.0 user knowledge and the limits of individual and collective power. First Monday, 21.

Rahmatizadeh, S. Rajabifard, A.; Kalantari, M. 2016. A conceptual framework for utilising VGI in land administration. Land Use Policy 56, 8189.

Rouse, L. J.; Bergeron, S. J.; Harris, T. M. 2007. Participating in the Geospatial Web: Collaborative Mapping, Social Networks and Participatory GIS. In: Schari, A. (Ed.); Tochtermann, K. (ed.). The Geospatial Web: How Geobrowsers, Social Software and the Web 2.0 are shaping the Network Society. Advanced Information and Knowledge Processing, Springer.

See, L.; Mooney, P.; Foody, G.; Bastin, L.; Comber, A.; Estima, J.; Fritz, S.; Kerle, N.; Jiang, B.; Laakso, M.; Liu, H.; Milcinski, G.; Niksic, M.; Painho, M.; Podor, A.; OlteanuRaimond, A.; Rutzinger, M. 2016.
Crowdsourcing, Citizen Science or Volunteered Geographic Information? The current state of Crowdsourced Geographic Information. ISPRS International Journal of Geo-Information 5, 123.

Sieber, R. 2006. Public Participation Geographic Informations Systems: A Literatura Review and Framework. Annals of the Association of American Geographers 96, 491-507.

Sieber, R.; Haklay, M. 2015. The epistemology(s) of volunteered geographic information: a critique. Geo: Geography and Environment 2, 122-136.

Sieber, R. 2015. Volunteered Geographic Information. In: International Cartographic Association book, International Map Year, 2015. Disponível em http://icaci.org, acessado em abril de 2016.

Suchan, T. A.; Brewer, C. A. 2000. Qualitative methods for research on mapmaking and map use. The Professional Geographer 52, 145-154.

Upton, A.; Dunham, I. M. 2015. Volunteered geographic information, urban forests, and environmental justice. Computers, Environment and Urban Systems 53, 65-75.

USGS, United States Geological Survey. 2017. The National Map Corps. Disponível em < nationalmap.gov/TheNationalMapCorps/>, acessado em janeiro de 2017.

Van Elzakker, C. P. J. M.; Griffin, A. L. 2013. Focus on Geoinformation Users: Cognitive and Use/User Issues in contemporary Cartography. GIM International 27, 20-23.

Warf, B. 2011. Geographies of global Internet censorship. GeoJournal 76, 1-23.

West, A. G.; Chang, J.; Venkatasubramanian, K. K.; Lee, I. 2012. Trust in collaborative web applications. Future Generation Computer Systems 28, 1238-1251.

Wolf, E. B.; Matthews, G. D.; Mcninch, K.; Poore, B. S. 2011. OpenStreetMap Collaborative Prototype, Phase One. U.S. Geological Survey, Open File Report 2011-1136. 23p.

Zook, M.; Graham, M.; Shelton, T.; Gorman, S. 2010. Volunteered Geographic Information and Crowdsourcing Disaster Relief: A Case Study of the Haitian Earthquake. World Medical \& Health Policy 2, 7-33. 